CONVERSANDO

COM A MÍDIA

\title{
O QUE É QUE ELA TEM?
}

HELENA MAFFEI CRUZ

Gestora do Noos São Paulo isfarçada ou diretamente, em voz alta ou apenas internamente, essa é a pergunta que fazemos quando nos deparamos com uma criança cuja aparência chama atenção por ser diferente do esperado. Um exemplo relativamente frequente dessa diferença é o da Síndrome de Down, cujas características fenotípicas são bastante conhecidas. Nesses casos tão logo nos damos conta, seja no elevador, restaurante, ou qualquer espaço público, desviamos o olhar como que nos desculpando com o adulto cuidador, geralmente a mãe, ou toda a família.

É como se disséssemos: desculpe, não estou olhando, tudo bem, pode prosseguir em paz.

Não ocorre o mesmo quando anomalias desconhecidas se nos apresentam. Entre elas, as da Síndrome de Apert, uma doença genética caracterizada por uma má formação na face, crânio, mãos e pés. Os ossos do crânio fecham-se precocemente, não deixando espaço para que o cérebro se desenvolva, causando uma pressão excessiva sobre ele. Além disso, os ossos das mãos e dos pés são colados. Ao nascer, a criança tem cabeça pontuda, os olhos saltados, anomalias nas orelhas. Para sobreviver, necessita de cirurgia imediata para abrir espaço para o cérebro que está comprimido e inúmeras outras para tentar restaurar partes do rosto, mãos e pés.

O desejo de ser bem-educados nos faz desviar o olhar lentamente, como se nossa atenção não tivesse sido chamada mas, inevitavelmente, voltamos a olhar, disfarçar, olhar, disfarçar. A mãe e, com o tempo, a própria criança sentem esse vai e vem constrangido e às vezes passam a evitar todo e qualquer contato com o espaço público, ou então encontram meios de se fortalecer chegando até a acabar com o jogo mudo dizendo alguma coisa que serve de resposta à pergunta que não foi feita - o que é que ela tem?

Minhas reflexões sobre como convivemos com esse tipo de diversidade foram feitas a partir de um livro e um filme. O livro é O que é que ele tem? Nele, Olivia Byington, com generosa honestidade, nos conta sua história como mãe de João, seu primeiro filho, que nasceu com Síndrome de Apert; o filme é Extraordinário, que narra a entrada na escola, pela primeira vez, aos dez anos, de um menino com síndrome que causa deformações semelhantes às de Apert, embora sem deformações nas mãos e pés.

Assim Olivia inicia seu relato:

João entrou em casa nos meus braços [...] Um apartamento iluminado por uma grande janela de onde se viam os jardins de Burle Marx do prédio vizinho. O quarto de rendas e bordados, o berço antigo de madeira protegido por um cortinado de príncipe, o toucador repleto de pequenos mimos para seus cuidados diários. [...] Era uma volta ao lar de onde ele tinha saído - ainda dentro de minha barriga, fazia quase dois meses. A 
sonda no estômago, a cabeça enfaixada com ataduras feito um turbante, os olhinhos saltados. Evitei os olhares dos vizinhos, do porteiro, eu não queria exibi-lo. Ainda era preciso que eu me acostumasse. [...] João sofreu em torno de vinte cirurgias. Tudo começou no parto. Era o fim de um alegre verão, e eu me sentia preparada. Só não podia adivinhar o bote que o destino armava. (p. 15)

Olivia descreve o parto para o qual estava preparada para que fosse "sem dor". A primeira decepção foi que, já com a cabeça encaixada, a criança era maior do que a bacia e foi necessária uma cesariana. Daí para frente tudo confuso. Os médicos, constatando a má formação do bebê, doparam-na fortemente. Muito vigilante, não se entregou completamente aos sedativos e ouvia frases sem sentido, como a chamada do cirurgião plástico Dr. Pitanguy. Para quê? Foram muitas horas que pareceram as mais longas de sua vida até acordar completamente e ouvir do marido, Miguel, a confirmação sinistra. Pediu para ver o bebê e reagiu mal. Não queria aquela coisa, queria o filho perfeito, o bebê que ia dormir no quarto cheio de fru-frus, rendas e babados. Não queria aquela coisa malformada, sem dedos nas mãos, com uma cabeça gigante e olhos saltados.

O pediatra trouxe a trouxinha do berçário e disse:

- É seu filho, você tem que aceitá-lo.

E Olivia - "Não quero. Ponto. Façam o que quiserem com isso".

Por 180 páginas, sem autopiedade, ou autoengrandecimento como mãe excepcional, acompanhamos a narrativa da menina rica, que se transformara em jovem livre dos anos 70 que morava com namorados, era cantora e vivia no meio alegre de artistas.

Foram realizadas mais de vinte cirurgias, algumas com resultado sofrível, algumas fora do Brasil.

A estadia em um apartamento em Nova York pós-cirurgia e sua percepção de como uma menina rica no Brasil não aprende nada acerca de cuidar de uma casa, pois sempre há uma ou mais empregadas para essa tarefa. Sua decisão de não abandonar a carreira de cantora, o fim do casamento e uma segunda relação com três filhos. A pergunta de João, chorando, depois de conhecer seu irmãozinho; difícil de ouvir e mais difícil de responder:

- Por que ele não é como eu?

Entre as inúmeras cirurgias sempre na intenção de melhorar, corrigir alguns erros, insucessos, com mais dor, às vezes culpa; a perda de muitos amigos incapazes de conviver com a dificuldade, compensada por outros com maior competência emocional para estar ao lado da saga de João.

Ler esse livro, além de nos emocionar com a história de Olivia e João, nos ensina que a enorme complexidade da vivência da autora e a singularidade do processo de cada mãe, de cada família, exigem uma escuta, além de solidária, informada pelo "não saber" (Anderson \& Goolishiam, 1998). Em termos práticos, convida-nos a jamais dizer à mãe ou família nessa situação: "Eu sei como você/s se sente/m."

Nós não sabemos o que o outro sente e muito menos em experiências com o impacto descrito no livro $O$ que é que ele tem? Com respeito e delicadeza, podemos chegar perto da viagem emocional da recusa ou desespero, da imensa dor ao aprendizado primeiro da sobrevivência e, quase sempre, com 
o tempo, de um amor feito de coragem, cuidado, defesa leonina contra o medo, a ignorância e o preconceito com que o filho ou filha vai ser recebido em inúmeras situações.

Lido o livro, assisti a Extraordinário, que apresenta a família de Aughie, um menino nascido com uma síndrome não nomeada no filme, que produz anomalia craniofacial, com ausência de defeito nas mãos ou nos pés. Aughie está com 10 anos e, até essa data, passou por inúmeras cirurgias, entretanto, ainda tem uma aparência que chama atenção pela posição oblíqua dos olhos, cicatrizes ao redor da boca e orelhas com formato estranho. Nunca foi para a escola, tendo sido alfabetizado e aprendido as demais disciplinas com sua mãe. Aughie tem uma irmã quatro anos mais velha que vive a típica experiência dos irmãos de crianças com necessidades especiais - desliza silenciosamente pela casa, cumpre todas suas obrigações, não cria problemas, sabe como é difícil ser olhada, ter suas conquistas assinaladas; às vezes a vemos entristecida, mas não deixa de ajudar o irmão em nenhuma circunstância e nunca se rebela contra as mudanças de planos em função das necessidades de Aughie.

A mãe que não descansou um minuto das tarefas de ensinar, apoiar, acompanhar em todos os tratamentos e cirurgias, o que conhecemos por breves flashbacks, tem o seu olhar afiadíssimo para todos os possíveis entraves no caminho de Aughie. Mandá-lo para a escola pela primeira vez no quinto ano é um desafio emocional e tanto; por expressões do rosto, muito controladas, percebemos sua ansiedade, mas ela não deixa de estimular o filho nesse novo desafio. O pai, também extremamente amoroso, faz um contraponto mais brincalhão. Em resumo, a família, depois de ter passado por todas as vicissitudes da criação de Aughie até a data apresentada no filme, convive corajosa e amorosamente.

Aughie vai para a escola e é alvo de olhares, zombarias, mas também de solidariedade e delicadeza por parte de dois meninos que, ficamos sabendo, foram escolhidos pelo diretor para garantirem alguma solidariedade. Daí em diante, cenas de bullying se alternam com outras de ajuda. Quando um menino faz uma provocação mais grave, é suspenso e seus pais são chamados. Como era de se esperar, eles são contrários à permanência daquela criança monstruosa que prejudicaria as outras crianças "normais".

$\mathrm{O}$ diretor demonstra inequivocamente sua tolerância zero ao maltrato. $\mathrm{O}$ professor da classe é atento e competente para incluir Aughie na turma, no que é ajudado pela inteligência e especial talento e seu conhecimento na área de ciências.

O filme caminha para um final feliz no qual o prêmio anual para o aluno que mais se destacou e mais contribuiu para o desenvolvimento de toda a classe é atribuído a Aughie. Ao mesmo tempo, a mãe, aliviada da tarefa cotidiana de ensiná-lo, recupera outro aspecto de sua vida deixado de lado por 10 anos e termina sua tese de doutorado. Saímos emocionados e esperançosos do cinema.

Como terapeuta familiar, penso que gostaria de conhecer o/a "colega" que teria ajudado essa família a se fortalecer, superar a decepção, o medo, as culpas, os descuidos de uns com os outros em função do foco de todos no menino. Enfim, o filme nos encanta, mas nossa experiência e o que nos ensina Olivia 
Byington é que o caminho para chegar a esse ponto é árduo, nem sempre com tanto êxito e com alta probabilidade de separação dos pais, e algumas dificuldades com os outros filhos.

Convido você a ler o livro, a ver o filme, e nos contar suas reflexões.

\section{REFERÊNCIAS}

Anderson, H.; Goolishian, H. (1998) O cliente é o especialista: a abordagem terapêutica do não-saber. In McNamee, S.; Gergen, K. (Orgs.) Terapia como construção social. Porto Alegre RGS: Artes Médicas.

Byington, 0. (2016). O que é que ele tem? Rio de Janeiro: Objetiva.

Chbosky, S. (2017). Extraordinário, Filme (113min), Santa Monica, CA: Lionsgate

Entertainment. EUA. (Baseado no romance Wonder de R. J. Palacio)

\section{HELENA MAFFEI CRUZ}

Terapeuta familiar, editora associada da NPS e gestora do Noos São Paulo Email: $\underline{\text { hmcruz@noos.org.br }}$ 